\title{
Investigation of the Flow In Cold Condition at the Exit of a Supersonic Combustor Test Bench
}

\author{
Jefte da Silva Guimarães ${ }^{1,3, \star}$, Valéria Serrano Faillace Oliveira Leite ${ }^{2}$, Dermeval Carinhana Junior ${ }^{1,3}$, \\ Marco Antônio Sala Minucci ${ }^{1}$
}

Guimarães JS Dㅡ https://orcid.org/0000-0003-2339-8018 Leite VSFO (1D https://orcid.org/0000-0002-7515-8879

Carinhana Junior D (D) https: / /orcid.org/0000-0003-3526-7613

Minucci MAS (D) https://orcid.org/0000-0003-4583-6314

\section{How to cite}

Guimarães JS, Leite VSFO, Carinhana Junior D, Minucci MAS (2020) Investigation of the flow in cold condition at the exit of a supersonic combustor test bench. J Aerosp Technol Manag, v12: e4820. https://doi.org/10.5028/jatm.v12.1190

\begin{abstract}
For studies of hypersonic flows and supersonic combustion in ground test facilities, three devices can be used as ram accelerators, shock tunnels and supersonic combustor test benches. These devices can reproduce, on the ground, similar conditions to those in real flight at a certain altitude and speed. In the case of the supersonic combustor test bench [SCTB], it simulates the same flow conditions inside the combustor of a scramjet. The SCTB consists basically of a combustion chamber or vitiated air generator unit, where the air is heated, and a nozzle, where the air is accelerated to the desired test speed. The supersonic combustor to be tested is directly coupled to the nozzle exit of the SCTB. Ultimately, it was necessary to use a transition piece to connect the nozzle to the combustor to be tested, because the nozzle exit has a circular section and the combustor entrance has a rectangular one. This work aims to present the process of characterizing the cold flow along the SCTB of the Institute for Advanced Studies (IEAv) using the schlieren technique. The interference of the transition piece in obtaining the required flow conditions at the exit of the SCTB or the entrance of the combustor was mainly evaluated.
\end{abstract}

KEYWORDS: Scramjet; Supersonic flow; Ground testing facilities; Supersonic nozzle; Schlieren technique.

\section{INTRODUCTION}

Currently, several countries are studying and developing vehicles capable of achieving ever faster flight speed regimes. In this scenario, the development of aspirated engines supersonic combustion ramjets (scramjets) stands out. These engines have their technology under development through technological demonstrators (Sutton and Biblarzs 2001). Scramjets are capable of reaching hypersonic speeds through supersonic combustion, being considered a variation of ramjet engines. The key difference between them is the flow rate at which combustion is carried out. In ramjets, the airflow in the combustion chamber reaches subsonic speeds while in scramjets the speed is supersonic (Santos 2008).

In Brazil, the Departments of Defense and Science and Technology defined the research in propulsion with aspirated air and in hypervelocity regimes a priority. The key objective is to dominate this technology, promoting greater technological equality with other nations (Brazil 2003). In this way, the development of scramjet technology remains the responsibility of the Institute for Advanced Studies (IEAv), having as main project the development of the hypersonic aerospace vehicle 14-X. This project is

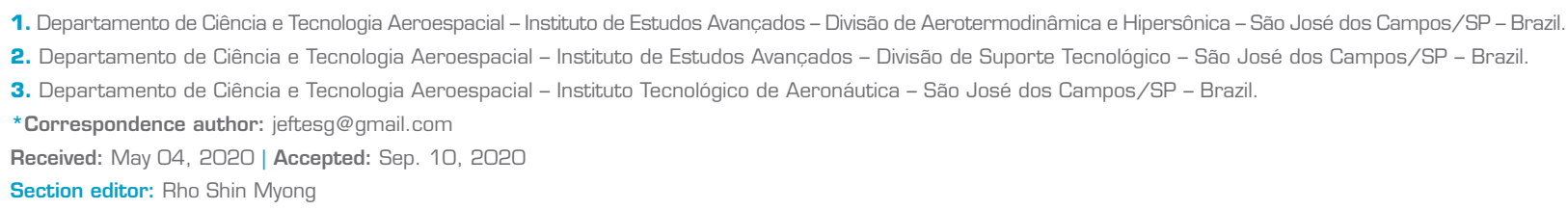


part of the effort by the Department of Aerospace Science and Technology (DCTA) to design a space exploration vehicle capable of taking off from spaceports.

To launch a technological demonstrator of a scramjet vehicle, preliminaries ground studies are required. In this way, it is possible to characterize the required conditions to which the vehicle will encounter in real flight situations. To carry out ground tests, enabling the study of supersonic flow and combustion, the IEAv has developed and operated several devices, such as hypersonic shock tunnels and supersonic combustor test benches (SCTB). These devices are essential, because they may enable ground tests on aerothermodynamic and hypersonic, allowing the development of airbreathing propulsion systems and aerodynamic tests of hypersonic vehicle reduced scales prototypes (Leite 2006).

Although the amounts spent on ground tests are much lower than in flight tests, the operating cost of some ground test facilities, as shock tunnels, are relatively high, particularly if the duration of the test is considered, around $1 \mathrm{~ms}$. In the case of SCTB, the problem of the duration time of the tests does not exist, since it is possible to carry out tests lasting 20 to $30 \mathrm{~s}$ or more, depending on the gas supply source of the bench, however this equipment is basically used to simulate the flow conditions at the entrance of a scramjet combustor, which correspond to the conditions of the atmospheric air flow behind the oblique or conical shock waves formed ahead of vehicles flying at hypersonic speeds on the vehicle. In this way, SCTB presents itself as an interesting device for the study of supersonic combustion, while the shock tunnels are more appropriate for the aerodynamic study of hypersonic vehicles.

\section{SUPERSONIC COMBUSTOR TEST BENCH [SCTB]}

Since the 1950s, the experimental study of supersonic combustion has been carried out in several countries (Curran 2001). Consequently, the SCTB has become an essential device.

The purpose of an SCTB is to produce the required flow condition for a direct connect test of a supersonic combustor. This phenomenon occurs behind the shock waves generated by the geometry of the scramjet vehicle at the supersonic nozzle outlet. This condition is the same as the flow at the entrance of the vehicle combustor. The flow is distinguished by its elevated temperatures and supersonic speeds. Therefore, the SCTB consists of a high enthalpy chamber, also known as vitiated air generator (VAG), where the air is heated and then accelerated by an associated supersonic nozzle. Furthermore, the VAG produces the required stagnation condition, at the inlet of the nozzle to make possible the flow achieves the desired test temperature and speed values (Leite 2006). In this IEAv arrangement, the combustor to be tested is coupled to the nozzle exit, which configures an SCTB of the directly connected type (Rogers et al. 1998).

Currently, research centers exhibit two distinct models of high enthalpy air generators devices. The first device uses the combustion process to generate the stagnation conditions, while the second one uses an electric arc for this purpose. Regardless the model adopted to obtain the high-temperature condition, the generated air is contaminated during the heating process, hence, the denomination "vitiated air". Disadvantages of an SCTB include air contamination by combustion products and electrode residues. Nevertheless, the generated flow must have the condition of pressures, temperatures, velocities and oxygen $\left(\mathrm{O}_{2}\right)$ molar fraction similar to the ones of the intake air at the entrance of the scramjet combustion chamber in real flight. Consequently, this allows the ground investigation of the supersonic combustion (MacDermott et al. 1992).

In an SCTB with electric arc type VAG, the increase in air enthalpy occurs through a high-voltage source connected to an anode and cathode positioned at the chamber ends, causing the air to be heated through the generated electric arc. In the sequence, the heated air passes through swirls, injectors that introduce turbulence in the system by means of the swirling movement, causing the mixture of hot air and the surrounding cold air to occur. Then, the air is accelerated until the desired conditions are reached by the supersonic nozzle, which feeds the combustor to be tested (Kidd et al. 2014).

The electric arc type VAG (Kidd et al. 2014) is the most suitable to study the supersonic combustion, as it produces a cleaner resulting gas compared to the combustion type VAG. However, the disadvantage is that it has a high operating cost due to the excessive consumption of electricity. To obtain a temperature of $4100 \mathrm{~K}$, for example, the consumption of the electrodes is at least $2500 \mathrm{~kW}$ per $\mathrm{kg} \cdot \mathrm{s}^{-1}$ of flow produced (Kirk 1968).

A simpler and more economical configuration can be obtained through SCTB with combustion type VAG, with good experimental results (Guimarães 1996). In this type of arrangement, the test temperature is reached by ignition of a liquid fuel (benzene, kerosene etc.) 


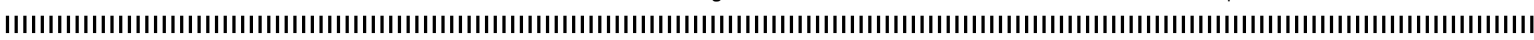

or gaseous fuel (hydrogen, propane, methane etc.). The test air flow needs to be previously enriched with $\mathrm{O}_{2}$ to replace the oxygen consumed in the combustion process inside the VAG. With this, it is possible to guarantee the $21 \%$ of $\mathrm{O}_{2}$ molar fraction in the flow at the exit of the SCTB, just like the atmospheric air. This condition is required to feed the combustor to be tested, so it is possible to carry out the supersonic combustion research on the ground (Baranovskii et al. 1988; Boyce et al. 1998).

Water is one of the biggest contaminants of the airflows generated in the VAG. It is a consequence of the burning fuels in the heating chamber, making it difficult to ignite the combustor (Baranovskii et al. 1988; Boyce et al. 1998). However, the presence of water can be mitigated by adjusting the reagents equivalence ratios. Thus, the effects of contaminated or vitiated air result in deviations below 5\%, considering the general performance of scramjet combustors (Tomioka 2007). The combustion type VAG stands out for its lower operating cost compared to the electric arc VAG and for its versatility, allowing the aerodynamic study of hypersonic systems and subsystems.

The SCTB installed in the IEAv (Fig. 1) consists of a combustion chamber (VAG) with a fuel injection plate at one end and a convergent-divergent supersonic nozzle at the other. This device produces, at the nozzle outlet, the required flow conditions behind the conical or oblique shock waves formed by technological demonstrators flying at hypersonic speeds. Typically, technological demonstrators have shapes that include frontal, conical or wedge geometries (Guimarães 2018). The conditions generated are the same as the airflow at the entrance of a scramjet combustor, having as main characteristics the elevated temperatures and supersonic speeds. The VAG serves to heat the air and the supersonic nozzle must accelerate the heated air to the conditions specified for the test.

The SCTB is a directly connected type, having a convergent-divergent nozzle designed to obtain with combustion Mach number of 2.6 and a temperature of $1040 \mathrm{~K}$. These are the same conditions obtained in preliminary experiments at the entry of the 14-X combustor model when tested in the T3 shock tunnel of the IEAv.

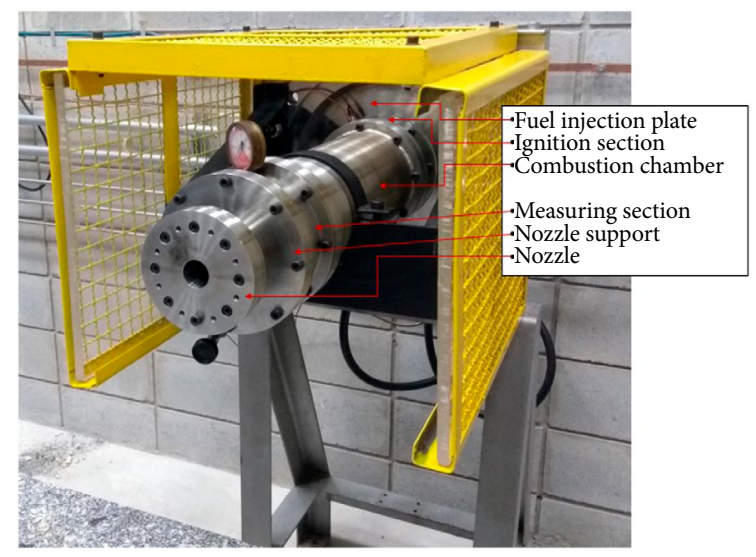

Figure 1. Supersonic combustor test bench (SCTB) pilot model used in IEAv.

\section{EXPERIMENTAL PROCEDURE}

The SCTB experimental apparatus (Fig. 2) illustrates the gas supply system and the model of the combustion used in the experiments. It is equally possible to observe the outside of the laboratory with the following cylinders: one for oxygen, two for compressed air, one for liquefied petroleum gas (LPG) and two for vehicular natural gas (VNG). These gases feed the fuel injection plate at the entrance of the VAG to obtain, after the combustion process, the pressure and the temperature stagnation conditions of the flow at the entrance of the nozzle. However, in the present work, the flow characterization was performed cold (without combustion), using exclusively compressed air and oxygen cylinders, to better evaluate the aerodynamic conditions of the flow along and at the exit of the SCTB. Inside the laboratory (Fig. 2), from left to right, the following items are observed: mass flow valves (a), flowmeters (b), the VAG, a flange with pressure sensors (measuring station) (1), a nozzle adapter (2), a convergent-divergent nozzle (3), a transition part from circular geometry out of the nozzle to the rectangular inlet geometry of the combustor (4) and the combustor model to be tested (5). 


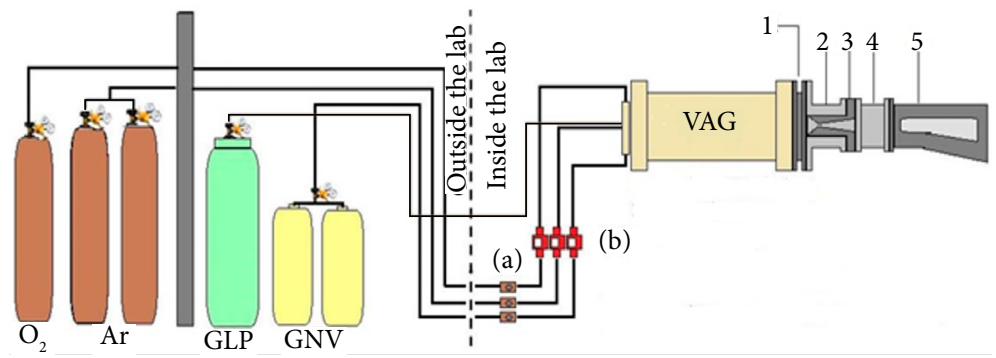

Figure 2. Scheme of the complete experimental apparatus for carrying out tests at the SCTB.

Because of cold flow characterization, three cylinders of compressed air were used. Thus, the $\mathrm{O}_{2}$ cylinder was replaced by the compressed air ones and no fuel was used.

\section{Transition part design}

The combustor model to be tested could not be connected directly to the nozzle because of its exit has a circular section and the inlet of the combustion has a rectangular one. In this manner, it was necessary to design an adaptation part to connect the nozzle outlet with the combustor inlet. Moreover, the adapter part must maintain a constant cross-sectional area along its length. In this way, it is possible to guarantee that there is no variation in the flow characteristics/conditions that are generated at the nozzle outlet. Therefore, the area of the circular cross-section of the nozzle exit and the height referring to the rectangular crosssection at the combustor inlet were considered. This height is $18.5 \mathrm{~mm}$ and corresponds to the height of one of the combustor models tested in the T3 shock tunnel of the IEAv. Therefore, the length of the rectangular cross-section can be easily calculated by Eq. 1, where $D$ is the diameter of the nozzle, $C$ is the length of the rectangular section and $\mathrm{H}$ the height of the rectangular section.

$$
\frac{\pi * D^{2}}{4}=C * H
$$

It is recognized that the diameter of the nozzle exit is $\emptyset 34.04 \mathrm{~mm}$ and the height of the rectangular section is $18.5 \mathrm{~mm}$. From Eq. 1 onwards, the transition piece must maintain an area of $910,057 \mathrm{~mm}^{2}$ along its entire length, that is, it must complete a smooth transition from the circular cross-section to the rectangular cross-section. To identify the influence of the total length of the transition piece on the flow conditions, two models were initially designed. The first model is $100 \mathrm{~mm}$ long and the second $150 \mathrm{~mm}$. The 2D technical drawings of the 100 and $150 \mathrm{~mm}$ models of the transition pieces, shown in Figs. 3a and 3b respectively, illustrate the variation of the circular up to the desired rectangular.
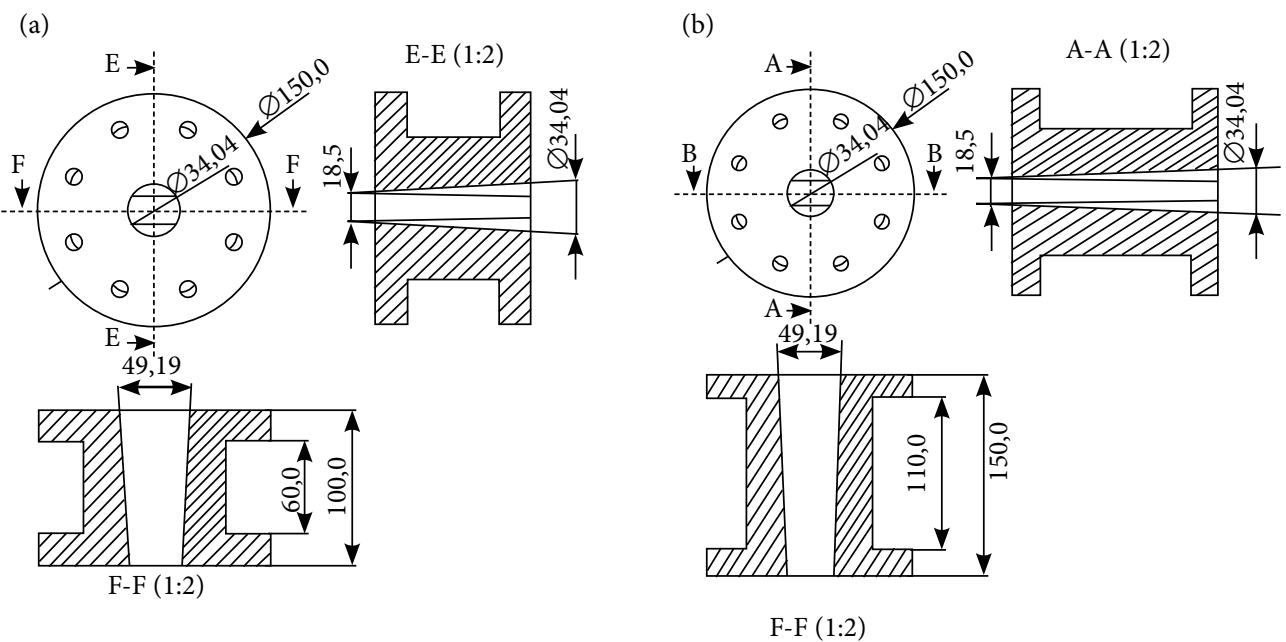

Figure 3. (a) Technical drawing of the $100 \mathrm{~mm}$ transition part; and (b) $150 \mathrm{~mm}$ transition part. 
In Fig. 4, a 3D sectional view of the $100 \mathrm{~mm}$ transition piece is shown, which allows a three-dimensional view of the variation from the circular section to the desired rectangular section.

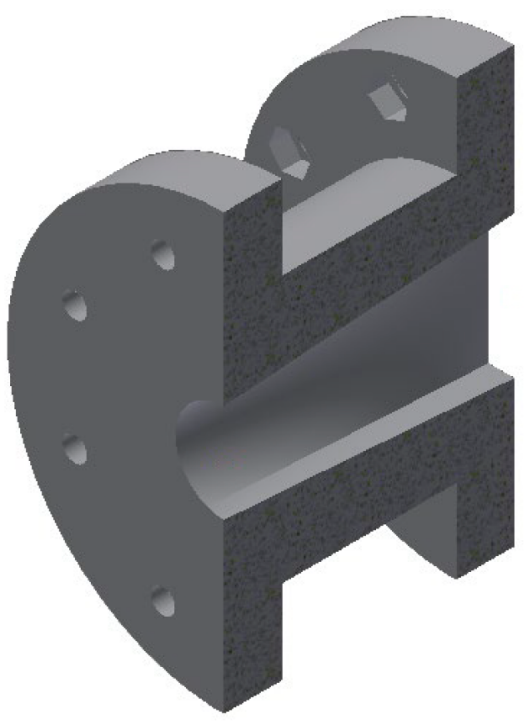

Figure 4. $3 D$ sectional view of the $100 \mathrm{~mm}$ transition part.

Considering that the experiment of the present work has been done in the cold flow condition, the transition parts and combustion were made employing the rapid prototyping system using a 3D printer Fortus 900mc from STRATASYS, applying the fused deposition modeling (FDM) technology, which is produced by the deposition of base material on a support that will later be discarded. The deposition is made layer by layer through heated extruder nozzles, at temperatures of around $673.15 \mathrm{~K}$. The material deposition environment is an oven that allows the control of appropriate temperature and ventilation so that the layers of the material are cooled uniformly (Marcos et al. 2017).

The transition parts (Fig. 5) and the combustor model (Fig. 6) were made using the thermoplastic material ULTEM 9085. This material has been employed for aerospace, automotive and military applications due to its FST (flame, smoke and toxicity) classification.

The combustor was developed to be coupled to the rectangular cross-section of the transition part. In this manner, it is possible to maintain a flange of $150 \mathrm{~mm}$ diameter and $10 \mathrm{~mm}$ thickness with the same drilling center used for the transition part. To visualize the flow behavior within the model tested, considering the cold flow, two acrylic windows were added on both sides of the model. This made possible to visualize the flow behavior through optical methods, such as the schlieren technique.
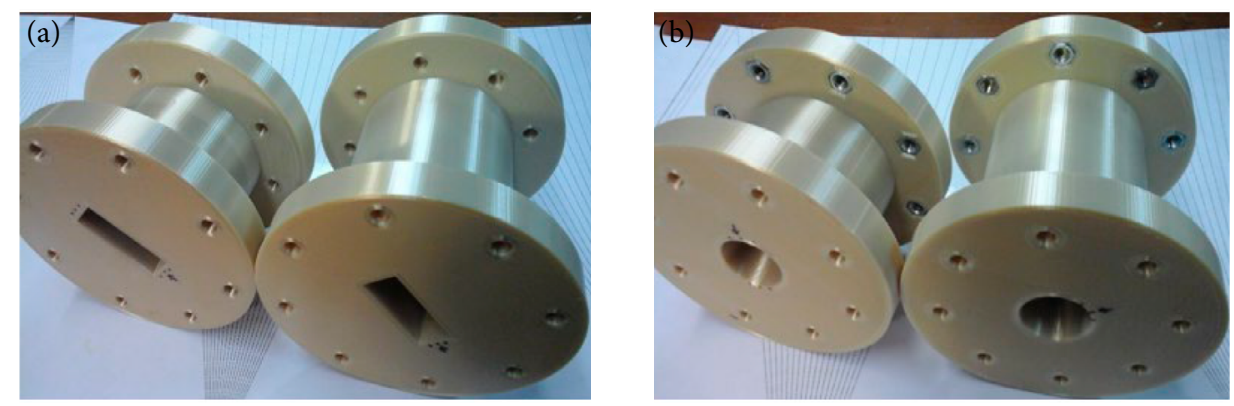

Figure 5. (a) Rectangular cross-section of the transition parts; (b) circular cross-section of the transition parts. 


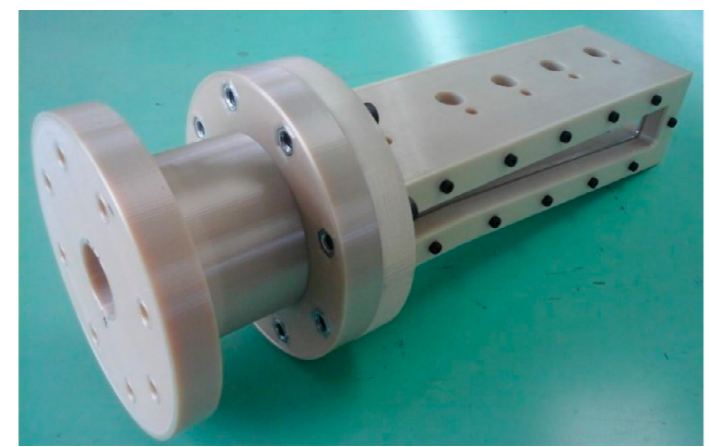

Figure 6. Assembly of the combustor coupled to the $100 \mathrm{~mm}$ transition part.

\section{Flow speed characterization}

To determine the Mach number, a wedge with the semi angle $\theta=15^{\circ}$ was initially positioned in front of the SCTB nozzle exit and then, using the transition parts coupled to the nozzle, the wedge was positioned at the exits of the transition parts. The length of the wedge used is equal to $150 \mathrm{~mm}$, being positioned in the center of the nozzle exit and then in the center of transition parts exits with a distance of $3 \mathrm{~mm}$. To visualize the shock wave formed over the wedge, the schlieren technique was applied, which makes it possible to measure the angle of the shock wave $\beta$ formed over the wedge.

The schlieren method is a nonintrusive optical technique for visualizing complex flows. It is based on the deviation of light that passes through a transparent medium with gradients of the refractive index. In this technique, optical devices, such as the combination of mirrors and/or lenses, are employed. These devices allow the flow visualization in the region where the light undergoes deflection due to the refractive index gradients. The deflection of the light is compared with the nondeflected light, making it possible to capture the flow development in images (Estruch et al. 2009). Furthermore, it is possible to create contrasts in the images that reveal the density variations generated in the flow that is being studied.

For the assembly of the schlieren technique next to the experiment, a set of three mirrors was used. Two mirrors had a diameter of $35 \mathrm{~cm}$ and the other a diameter of $10 \mathrm{~cm}$. The focal length used was approximately $180 \mathrm{~cm}$. The following devices were also used: a light-emitting diode (LED) light source, a spatial filter called "knife" to block out the deviated light rays, a high-speed camera and a computer for data storage. The schlieren images were obtained through the optical arrangement combined with a high-speed PCO camera/DIMAX HS.

The knife edge is essentially used to regulate the contrast of the images that will be obtained. The contrast increases with the number of deflected rays that are blocked by the knife. Therefore, the contrast decreases inversely. The image produced in the camera is a two-dimensional image. This is equally related to the sensitivity of the camera used. Consequently, both camera and knife are essential tools for carrying out the schlieren technique. The knife edge must be positioned along the principal axis of the mirror/ lens so that the ideal focal plane is obtained. When the focal plane is provided, the images on the screen are presented uniformly, without optical aberrations (Machado 2014; Resende and Vilarinho 2005).

Once the angle $\beta$ of the shock wave formed on the ramp was measured, the flow Mach number can be calculated. This was done both at the exit of the nozzle and the exit of the transition pieces, through Eq. 2 , called equation $\theta-\beta-M$. The flow was considered calorically perfect, so $\gamma=1.4$.

$$
\tan \theta=2 \cot \beta \frac{M_{1}^{2} \sin ^{2} \beta-1}{M_{1}^{2}(\gamma+\cos 2 \beta)+2}
$$

As the cold flow characterization was considered, the stagnation temperature $T_{0}$, at the entrance of the nozzle, can be equal to $298.15 \mathrm{~K}$ and the temperature $T_{\mathrm{s}}$ at the nozzle exit was estimated by Eq. 3. The outlet pressure $p$ was estimated by Eq. 4 , having the stagnation pressure $p_{0}$ measured with a manometer.

$$
\frac{T_{0}}{T}=1+\frac{\gamma-1}{2} M_{1}^{2}
$$




$$
\frac{p_{0}}{p}=\left(1+\frac{\gamma-1}{2} M_{1}^{2}\right)^{\frac{\gamma}{(\gamma-1)}}
$$

Initially, the experiments were conducted to characterize the flow at the nozzle outlet. These were carried out under the condition of a free jet flow, which consists of the expansion of a fluid through a nozzle to a specific environment. In this case, the flow is directly unaffected by a fixed contour. In all experiments performed, the flow generated was released directly into the atmosphere, and a diffuser was not used to match the pressure of the nozzle outlet with the ambient pressure. Moreover, experiments with the $100 \mathrm{~mm}$ (T-100) and $150 \mathrm{~mm}$ (T-150) transition pieces were respectively performed. Subsequently, the cold tests were carried out with the prototyped combustor. A ramp with a $\theta=15^{\circ}$ semiangle was positioned at a distance of $3 \mathrm{~mm}$ from the nozzle, the T-100, and the T-150 exits. The experiments were carried out with three pressurized compressed air cylinders.

The SCTB was instrumented with two pressure manometers. The first one was positioned at the entrance of the combustion chamber or VAG, before the fuel injection plate, where the pressure of the system inlet $\left(p_{\mathrm{p}}\right)$ was registered. The other manometer was positioned at the entrance of the nozzle, where the stagnation pressure $\left(p_{0}\right)$ was recorded. The pressure value recorded by the manometer during the experiments at the nozzle inlet for the four cases (nozzle, T-100 and T-150 transition pieces and combustor model exits) was $p_{0}=500 \mathrm{kPa}$.

The results obtained experimentally and using Eq. 2 for the Mach number and Eq. 3 the temperature were compared with the values calculated through the computer program Bocal_GAV developed in MATLAB by (Leite 2006). This program calculates the flow conditions along a convergent-divergent nozzle, for a defined pressure and stagnation temperature. The flow inside the nozzle can be considered and/or treated as: calorically perfect, thermally perfect, in equilibrium, frozen or in nonequilibrium, depending on the conditions of stagnation of the problem to be studied. In the case of the present work, for the analysis of cold flow, the calorific perfect program module was used.

\section{FLOW ANALYSIS AT THE NOZZLE EXIT}

The pressure values recorded by the manometers during the experiments were $p_{\mathrm{p}}=690 \mathrm{kPa}$ ( 6.9 bar), at the entrance to the chamber, and $500 \mathrm{kPa}$ (5 bar), at the entrance of the nozzle.

To determine the experimental Mach number, a set of five images generated in each experiment was analyzed. Once the angle $\theta$ is known and the angle $\beta$ was visualized by the schlieren method, the Mach number can be calculated using the $\theta-\beta-M$ ratio (Eq. 2). To allow the analysis, the upper and lower semiangles were checked computed in the calculations performed.

Figure 7a shows a schlieren image with the indications of the angles used for the analysis of the Mach number. In this case, $\theta_{s}$ and $\theta_{i}$ represent, respectively, the upper and lower semiangles of the test ramp. $\beta_{\mathrm{s}}$ and $\beta_{\mathrm{i}}$ represent, respectively, the upper and lower shock wave angles. Figure $7 \mathrm{~b}$ represents one of the schlieren images obtained in the experiment, identifying the formation of the shock wave over the test ramp.

In the schlieren image, it is observed that the flow generated an underexpanded flow. It can be classified this way because the flow structures visualized in the schlieren image are not typically seen in perfectly expanded and overexpanded flows. Therefore, it is an exclusive characteristic of underexpanded flows, which explains the visibility of oblique shock waves only close to the leading edge of the wedge. After this region, outside the free jet, the flow deteriorates.

Based on the pressure measured by the pressure gauge at the nozzle inlet, the stagnation pressure of $p_{0}=500 \mathrm{kPa}(5 \mathrm{bar})$ was obtained. Considering the atmospheric pressure measured by a barometer in the laboratory is equal to $93 \mathrm{kPa}\left(0.93\right.$ bar), the pressure ratio $p_{0} / p$ is equal to 5.38. Considering the isentropic pressure ratio (Eq. 4), a Mach number equal 1.76 was calculated, the same being represented in Table 1 as an analytical value. For the calculation of the outlet temperature $T_{s}$, three variables were considered: the Mach number obtained in the experiment, the stagnation temperature $T_{0}$ equal to the ambient temperature at the time of the tests, being $T_{0}=298.15$, and the temperature $T_{s}$, at the nozzle exit, that was calculated using Eq. 3. Thus, the temperature $T_{s}$ obtained for the flow at the nozzle outlet was $179.39 \mathrm{~K}$. This value is represented in Table 1 as an experimental value. The comparison of the analytical values with the values found experimentally is provided in Table 1 , where it is identified that for the case presented the values obtained by the methodology are close to the analytical values, reinforcing its efficiency. The Mach number considered for the experiments represents the average of the Mach numbers obtained from the schlieren images, for each experiment. The Mach numbers and its respective standard deviations are shown in Table 2. 
(a)

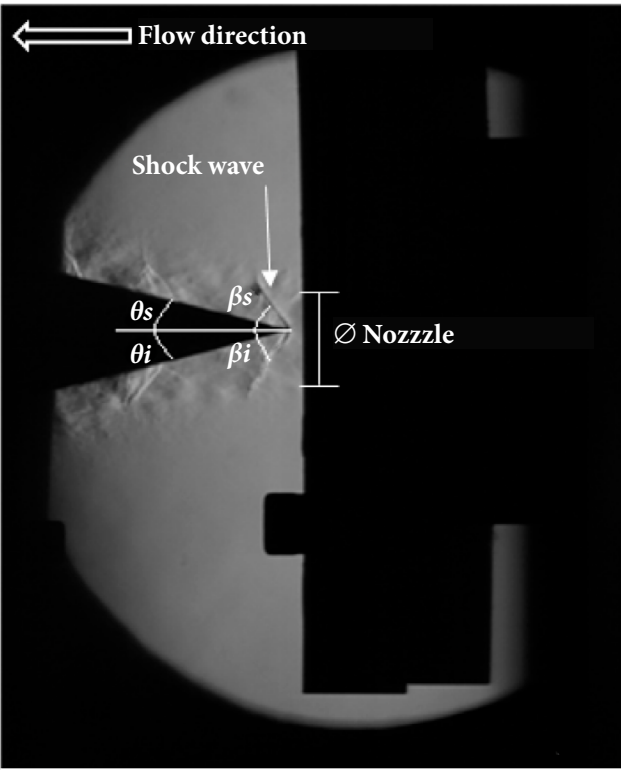

(b)

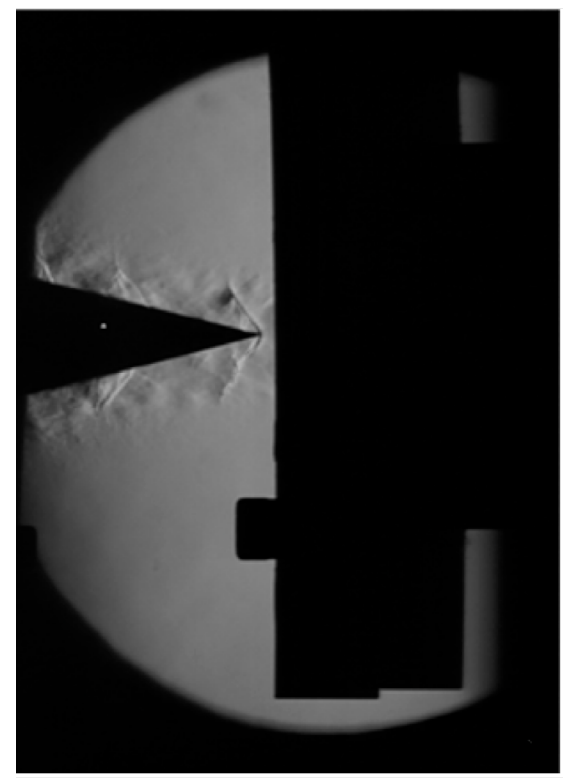

Figure 7. Schlieren image with the points under analysis (a), example of the images obtained in the experiments (b).

Table 1. Comparison of theoretical and experimental results at the nozzle outlet.

\begin{tabular}{|c|c|c|c|c|}
\hline Analyze & $\mathrm{p}_{\mathrm{o}} / \mathrm{p}$ & $\mathrm{T}_{\mathrm{o}} / \mathrm{T}_{\mathrm{s}}$ & Mach & ${ }^{*} \mathrm{~T}_{\mathrm{s}}(\mathrm{K})$ \\
\hline Analytical & 5.40 & 1.62 & 1,76 & 184.04 \\
\hline Experimental & 5.38 & $1.66 \pm 0.04$ & $1.82 \pm 0.05$ & $179 \pm 5$ \\
\hline
\end{tabular}

* Calculated using the Mach number found experimentally.

Table 2. Experimental determination of the Mach number.

\begin{tabular}{|c|c|c|c|c|}
\hline Image & x (pixel) & beta (pixel) & Mach \\
\hline 7489 & 33 & 38 & 49.02 & 1.86 \\
\hline 7489 & 31 & 38 & 50.79 & 1.81 \\
\hline 8002 & 19 & 26 & 53.84 & 1.74 \\
\hline 8002 & 33 & 41 & 51.17 & 1.80 \\
\hline 8015 & 26 & 35 & 53.39 & 1.75 \\
\hline 8015 & 15 & 20 & 53.13 & 1.86 \\
\hline 9483 & 33 & 38 & 49.02 & 1.85 \\
\hline 9483 & 37 & 43 & 49.29 & 1.94 \\
\hline 9671 & 34 & 36 & 46.63 & 1.84 \\
\hline 9671 & 32 & 38 & 49.90 & $1.82 \pm 0.05$ \\
\hline
\end{tabular}




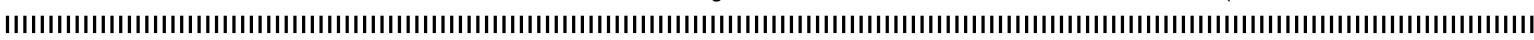

With the same stagnation conditions of the experimental tests, being $p_{0}=500 \mathrm{kPa}$ ( $5 \mathrm{bar}$ ), $T_{0}=298.15$ and $\gamma=1.4$, the program Bocal_GAV was utilized to calculate the temperature conditions and the Mach number at the nozzle outlet. For this calculation, 4,000 interactions were carried out to guarantee data convergence. Figure 8 shows the generated results for the Mach number. Conditions on the centerline are analyzed, as the test ramp is positioned in the center of the nozzle where the data are obtained. Therefore, it was identified that the flow reached $M=1$ at the nozzle throat ( $x$-axis: $0.02543 \mathrm{~m}$ ). This is the necessary condition for the flow to be accelerated by the divergent region of the nozzle. Looking at the color bar on the right side of the image, it can be seen that the Mach number at the nozzle wall corresponds to $M=2.6$. This result was expected since the nozzle was designed considering the areas ratio $\left(A / A^{*}\right)$ correspondent to this Mach value, where $A^{*}$ is the area of the throat and $A$ the nozzle exit area. The Mach number obtained in the center of the nozzle exit was $M=1.94$, which is close to the values found experimentally and theoretically.

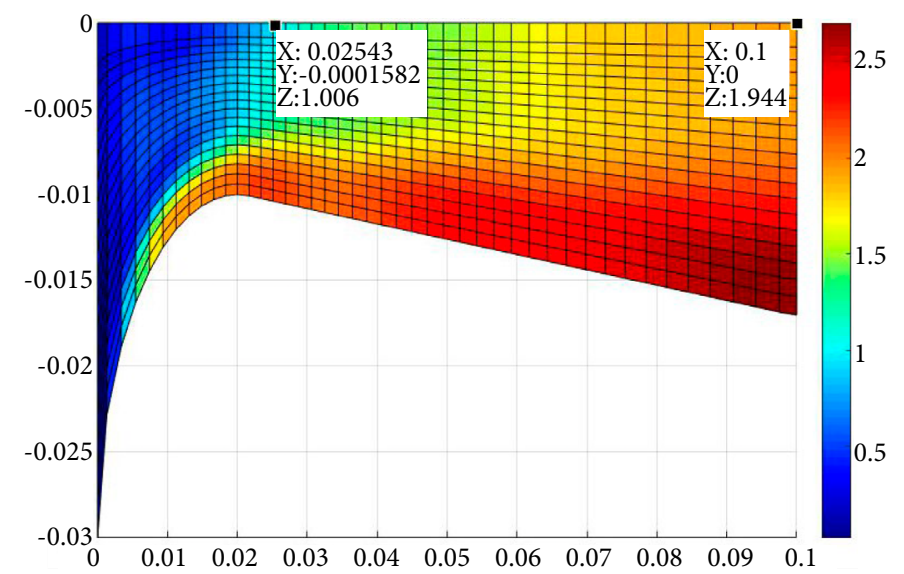

Figure 8. Matlab simulation of the Mach number along the nozzle for $p_{0}=500 \mathrm{kPa}$ using the program Bocal_GAV.

Figure 9 presents the temperature result for the same stagnation conditions used to the calculation of the Mach number. With the simulation performed, the temperature obtained at the center of the nozzle exit was $T_{\mathrm{s}}=154.5 \mathrm{~K}$. Table 3 shows the comparison of temperature data and Mach number obtained analytically, experimentally and through simulation with the Bocal_GAV program.

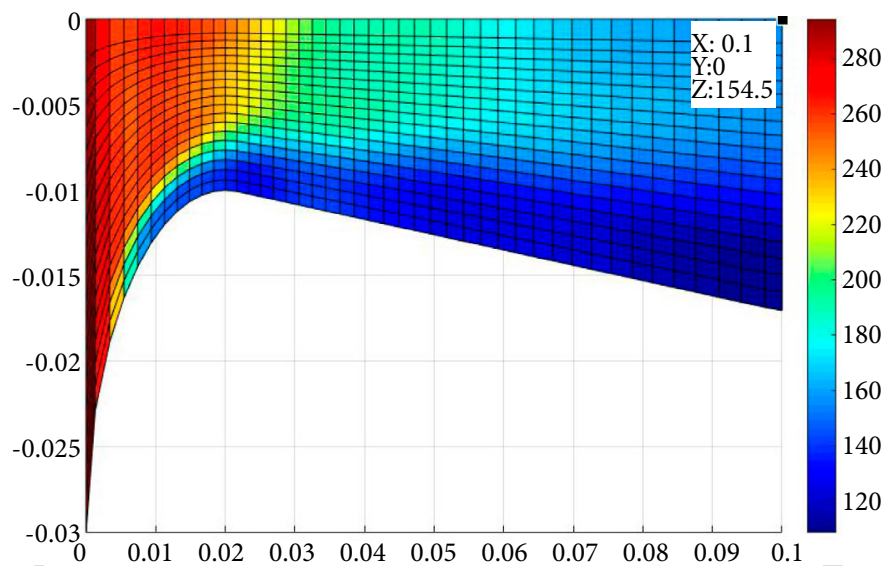

Figure 9. Matlab simulation of the temperature along the nozzle for $p_{0}=500 \mathrm{kPa}$ using the program Bocal_GAV.

Considering the experimental values as a reference, Table 3 shows that both the Mach number and the temperature values at the nozzle outlet $\left(T_{s}\right)$ are similar for the three situations (experimental, analytical and 2D simulation). The difference obtained for the Mach number is $6.59 \%$ and for $T s$, it is $13.85 \%$. 
Table 3. Comparison of Mach number and temperature values at the nozzle outlet.

\begin{tabular}{|c|c|c|c|c|}
\hline Analyze & Mach & Comparison & $\mathrm{T}_{\mathrm{s}}(\mathrm{K})$ & Comparison \\
\hline Experimental & $1.82 \pm 0,05$ & Reference value & $179 \pm 5$ & Reference value \\
\hline Analytical & 1.76 & $-3.29 \%$ & 184.04 & +2.62 \\
\hline 2D Simulation & 1.94 & $+6.59 \%$ & 154.50 & $-13.85 \%$ \\
\hline
\end{tabular}

\section{Flow analysis at the exit of transition parts}

After the experimental tests with the nozzle, the same tests were carried out with the transition pieces (T-100 and T-150). The objective was to identify a possible change in the behavior of the flow conditions, especially of Mach number, at the exit of the nozzle and the exit of the transition pieces. The ambient pressure and temperature conditions were considered to be $93 \mathrm{kPa}(0.93 \mathrm{bar})$ and $298.15 \mathrm{~K}$ respectively for the tests with both transition parts (T-100 and T-150). The stagnation temperature $\left(T_{0}\right)$ was considered $298.15 \mathrm{~K}$.

The test ramp was the same used in the tests at the nozzle outlet, with the same angle, $\theta=15^{\circ}$. It was positioned at a distance of $3 \mathrm{~mm}$ in both experiments. To determine experimental Mach number, it was analyzed a set of five images generated in each experiment. Once the $\theta$ angle is known and the $\beta$ angle was visualized by the schlieren method, the Mach number can be calculated by the $\theta-\beta-M$ relationship (Eq. 2). In the same way, the upper and lower semiangles of the ramp were checked, and they were computed in the calculations performed.

Figure 10 displays a schlieren image with the indications of the angles used for the analysis of the Mach number on the T-100. Figure 11 represents one of the schlieren images for the case of the T-150 obtained in the experiment; arrow shows the shock wave formed over the test ramp.

(a)

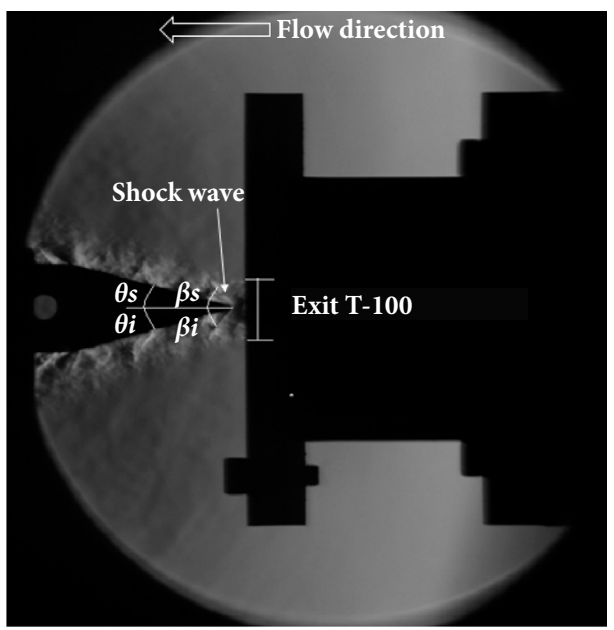

(b)

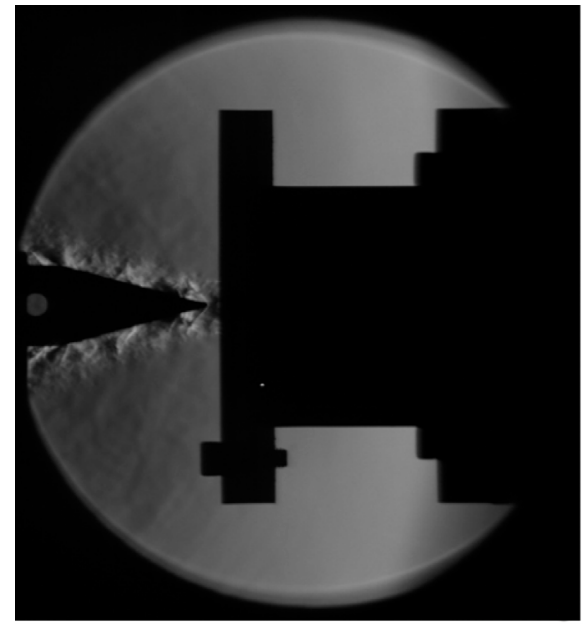

Figure 10. Schlieren image with the points under analysis on the T-100 (a), example of the images obtained in the T-100 experiments (b).

Based on the pressure measured at the inlet of the nozzle, the stagnation pressure, $p_{0}=500 \mathrm{kPa}(5 \mathrm{bar})$, was obtained. Considering that the atmospheric pressure measured by a barometer in the laboratory is equal to $93 \mathrm{kPa}(0.93 \mathrm{bar})$, the pressure ratio $p_{0} / p$ is equal to 5.38. So, from the isentropic pressure ratio (Eq. 4), a Mach number 1.76 was obtained, the same being represented in Table 4 as an analytical value for the exit of the nozzle.

For the calculation of the outlet temperature $T s$, the Mach number obtained in the experiment, the stagnation temperature $T_{0}$ equal to $298.15 \mathrm{~K}$ and the temperature $T s$ calculated by Eq. 3 were considered. This value is shown in Table 4 as experimental. The comparison between the analytical and experimental values is also provided in Table 4 , where it can be noted that the analytical and experimental values remained almost the same for the two transition pieces. 
(a)

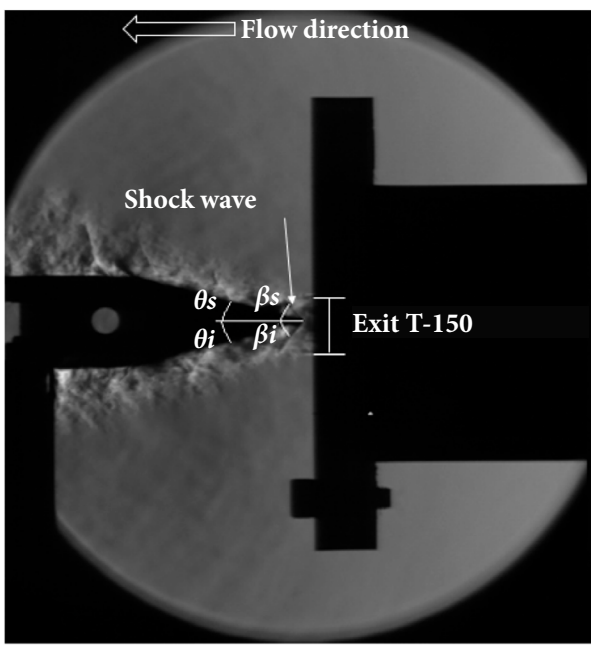

(b)

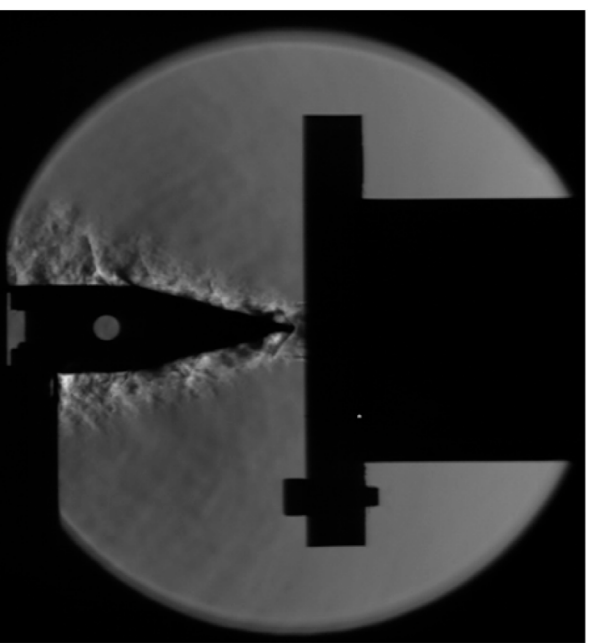

Figure 11. Schlieren image with the points under analysis of the T-150 (a), example of the images obtained in the T-150 experiments (b).

Table 4. Comparison of Mach number and temperature values at the exit of transition parts T-100 and T-150.

\begin{tabular}{|r|c|c|c|c|c|}
\hline Component & Analyze & $\mathrm{p}_{\mathrm{o}} / \mathrm{p}$ & $\mathrm{T}_{\mathrm{o}} / \mathrm{T}_{\mathrm{s}}$ & Mach & * $\mathrm{T}_{\mathrm{s}}(\mathrm{K})$ \\
\hline \multirow{2}{*}{$\mathrm{T}-100$} & Analytical & 5.40 & 1.62 & 1.76 & 184.04 \\
\hline & Experimental & 5.38 & $1.67 \pm 0.06$ & $1.83 \pm 0.07$ & $178 \pm 7$ \\
\hline \multirow{2}{*}{$\mathrm{T}-150$} & Analytical & 5.40 & 1.62 & 1.76 & 184.04 \\
& Experimental & 5.38 & $1.72 \pm 0.03$ & $1.90 \pm 0.04$ & $173 \pm 4$ \\
\hline
\end{tabular}

With the results obtained for both cases (T-100 and T-150), they were compared with the Mach number obtained for the nozzle exit. The points represented in Fig. 12 are related to the ten measurements obtained (lower and upper half angles of five experiments) for each case (nozzle, T-100, and T-150). The final Mach number considered for each one was the average of the Mach numbers calculated relative to the analyzed images, being indicated on the $y$-axis of the graphic in Fig. 11.

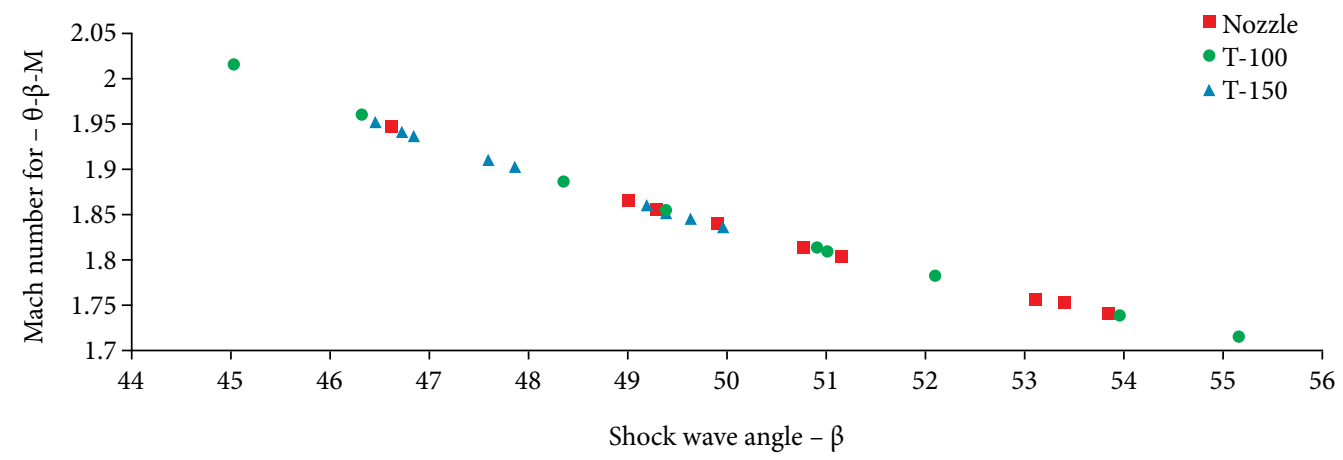

Figure 12. Graphic of the Mach number found in the experiments using the schlieren technique.

Considering the average Mach numbers, the values of $M=1.82,1.83$ and 1.90 were obtained, respectively, for the nozzle outlet and the transition pieces T-100 and T-150. Thus, it was possible to identify, using the schlieren technique and the $\theta-\beta-M$ equation, that there was an increase in the flow Mach number for the experiments carried out on the transition pieces T-100 and T-150 compared to the flow Mach number at the nozzle outlet. 
It was observed that the largest Mach number obtained was at the outlet of the T-150 part and the lowest was at the nozzle outlet. The difference between these values is equal to 0.08 . It represents a $4.4 \%$ increase in the flow velocity at the exit of the transition piece T-150 concerning the flow velocity at the nozzle exit. The values of Mach number and shock wave angle $\beta$ obtained by the presented methodology, when comparing the equations (Eqs. 3 and 4) calculated by the isentropic relations of pressure and temperature and the equation $\theta-\beta-M$ (Eq. 2), it is possible to verify that the values found experimentally are very close to the analytical ones.

Based on the results of the analysis of the transition pieces (T-100 and T-150), the T-100 part was selected. This choice occurred due to the difference between the Mach number for the piece T-100 and the Mach number at the nozzle outlet, and this value was 0.01 , lower than the value found for the piece T-150. It is observed, however, that even finding that the T-100 part is the better option, the difference in the Mach number at the exit of the T-150 part, comparing to the Mach at the nozzle exit, was less than $5 \%$.

\section{Flow analysis at the combustion outlet}

After performing the analysis of the transition parts and verifying the T-100 showed a smaller variation in the Mach number of the flow at its outlet, the model of the combustor to be tested was coupled to T-10, as show in Fig. 13. All experiments carried out on the combustor model used the T-100 transition piece to couple the nozzle exit to the combustor model to be tested. Fig. 12 shows the complete assembly of the combustor coupled to the SCTB.

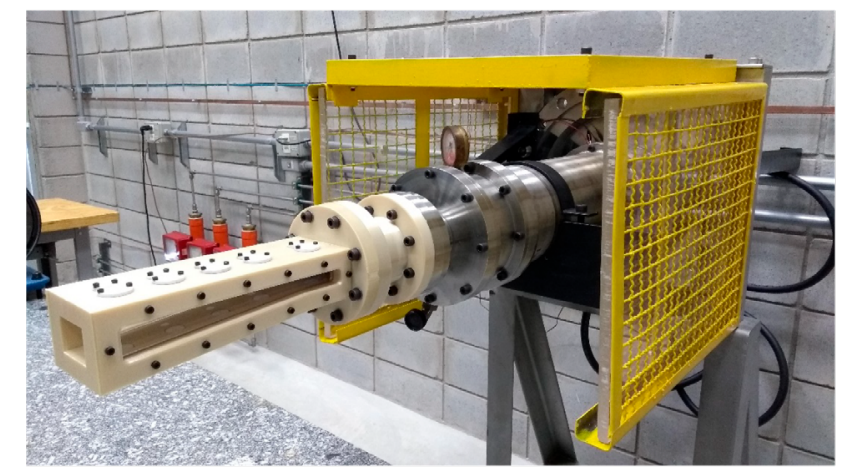

Figure 13. Supersonic combustor coupled to the SCTB using the transition part T-100.

The experimental tests of the combustor were initially conducted to visualize the flow behavior within the model tested. In these experiments, it was verified if there is supersonic flow inside the internal section of the model (straight section), with parallel walls, where theoretically hydrogen injection would occur in a supersonic combustion test. This is the necessary condition for the propulsion of scramjet vehicles.

Figure 14 shows the shock and expansion waves formation through the model of the tested combustor. Considering the previous analysis performed on the transition piece (T-100) to be used together with the combustor, it can be stated that the flow generated in at the exit of the SCTB is the same at the exit of the transition piece T-100, so, is the same at the entrance the combustor model. Therefore, it is a supersonic flow, as it can be seen in Fig. 14, especially at the exit of the straight section.

After the tests to visualize the flow behavior along the combustor, the tests with the methodology using the test ramp, in the same way that was done for the nozzle and the transitions pieces, were carried out. These tests aimed to determine the Mach number at the combustor model exit. In the experimental tests, the ambient pressure and temperature conditions were considered to be $93 \mathrm{kPa}(0.93$ bar) and $298.15 \mathrm{~K}$.

The test ramp was positioned at a distance of $3 \mathrm{~mm}$, following the corresponding distance used in the tests at the exit of the nozzle, and the exit of the transition parts, with the angle of the same $\theta=15^{\circ}$. 
(a)

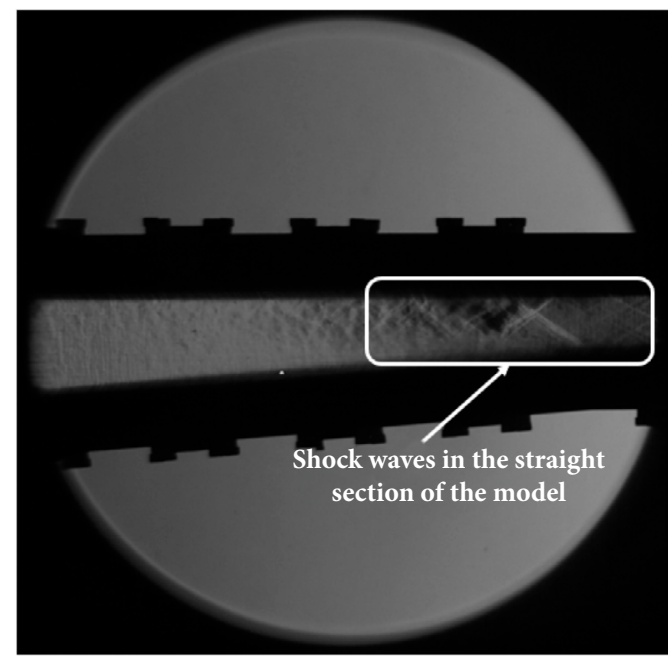

(b)

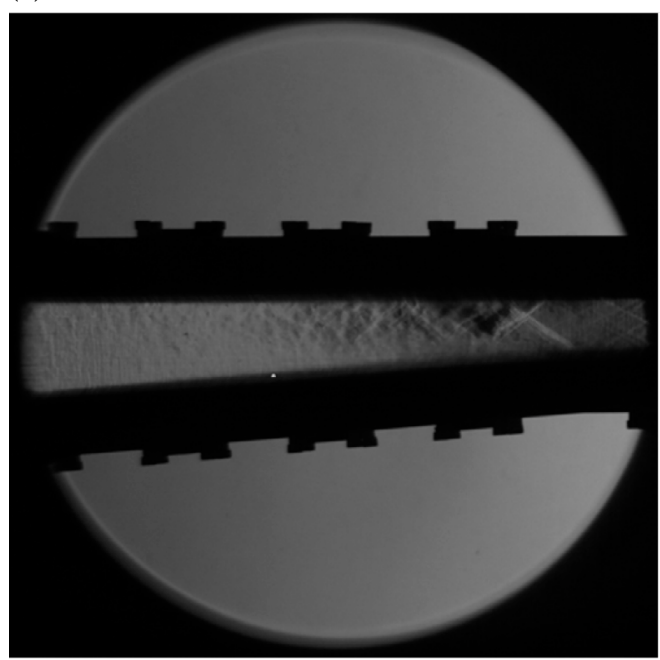

Figure 14. Flow visualization through the combustor model window.

Figure 15 shows a sequence of three schlieren images obtained in the experiments. However, with the adopted methodology, it was not possible to visualize the formation of an oblique shock wave on the test ramp. In this case, only the formation of expansion waves was observed at the end of the ramp. The flow visualized through the window of the scramjet combustor model represents the end part of this window, representing a length of about $220 \mathrm{~mm}$, not being seen, in the images, the straight section of the combustor, but only the final expansion section.

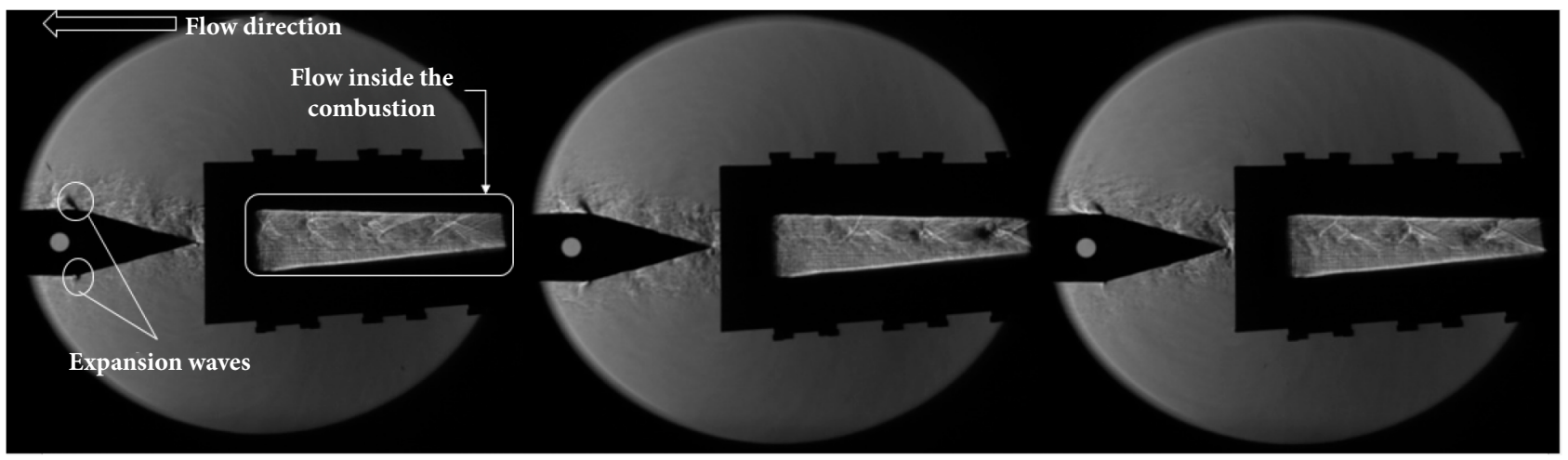

Figure 15. Flow visualization at the combustor model exit.

\section{FINAL CONSIDERATIONS}

The manufacture of the parts used for the flow analysis, using the 3D prototyping technique (the transition parts T-100 and T-150 and the combustion model) was effective. Through this technology, it was possible to quickly manufacture parts with complex geometries. This was only possible because the flow was analyzed in cold condition. Naturally, when combustion tests are carried out, such parts must be machined from metal.

The $\theta-\beta-M$ equation associated with the schlieren technique visualization is shown to be an important tool for preliminary characterization of the flow Mach number. This methodology met the objective initially proposed in this work, which was to evaluate the possible interference that the transition piece could cause in the test flow conditions, especially of Mach number. 
This transition piece will be located between the nozzle of an SCTB and the model of the combustor to be tested. Thus, it was possible to identify the real value of the Mach number of the flow that feeds the combustor.

The methodology used proved to be efficient to characterize the supersonic flow at the exit of ground test facilities, such as the SCTB. In the future, it will be necessary to compare the results obtained with other more sophisticated techniques. It is also noteworthy that the difference found between the Mach number obtained from the flow at the outlet of the nozzle and the exits of the transition pieces (T-100 and T-150) can be attributed to the manufacturing process of these. In its initial design, the area along the entire part, from the circular section to the rectangular section, should be equal to $910.057 \mathrm{~mm}^{2}$. However, after dimensional analysis, it was identified that, through the $3 \mathrm{D}$ prototyping process, the measured area was $914.44 \mathrm{~mm}^{2}$, which represents a variation of $0.48 \%$.

The work and methodology presented proved to be feasible to characterize the Mach number of the IEAv SCTB. This will enable the SCTB to be completed, making it possible to initiate supersonic combustion experimental studies on the ground. However, before the tests with combustion to heat the air inside the VAG, the SCTB will be instrumented with devices that are able to assist in the collection of important data of the flow test, thus making it possible to better validate the flow that is being generated at the exit of the SCTB. With this, the supersonic combustion can be investigated within the combustor model of the hypersonic demonstrator vehicle 14-X, that under development at the Aerospace and Hypersonics Division of the IEAv.

\section{ACKNOWLEDGMENTS}

The authors would like to thank the Institute for Advanced Studies (IEAv), the Division of Aerothermodynamics and Hypersonics (EAH), the Division of Technological Support (SUTEC)

Editors and authors are thankful to Fundação Conrado Wessel for providing the financial support for publishing this article.

\section{FUNDING}

Coordenação de Aperfeiçoamento de Pessoal de Nível Superior

Comando da Aeronáutica

\section{AUTHOR'S CONTRIBUTION}

Laboratory research, data collection, and analysis: Guimarães J S and Leite VSFO.; Orientation, supervision of research activities: Leite VSFO; Carinhana DJ and Minucci MAS., Technical discussions and Writing: Guimarães JS; Leite VSFO.; Carinhana DJ and Minucci MAS.

\section{REFERENCES}

\footnotetext{
Baranovskii SI, Nadvorskiil AS, Romashkova DD (1988) A simple one-dimensional model of the air contamination effect on supersonic combustion. Combust Explos Shock Waves 24(6):677-685. https://doi.org/10.1007/BF00740409

Boyce RR, Wendt M, Paull A, Chinzei N, Stalker RJ, Miyajima H (1998) Supersonic Combustion - A Shock Tunnel and Vitiation-heated Blowdown Tunnel Comparison. Paper presented 36th Aerospace Sciences Meeting \& Exhibit. AlAA; Reno, Nevada. https://doi. org/10.2514/6.1998-941
} 
Brazil. Ministério da Defesa; Ministério da Ciência e Tecnologia (2003) Concepção Estratégica: ciência, tecnologia e inovação de interesse da Defesa Nacional. Brasília: Ministério da Defesa.

Curran ET (2001) Scramjet engines: the first forty years. J Propul Power 27(6):1138-1148. https://doi.org/10.2514/2.5875

Estruch D, Lawson NJ, Garry KP (2009) Application of optical measurement techniques to supersonic and hypersonic aerospace flows. J Aerosp Eng 22(4):383-395. https://doi.org/10.1061/(ASCE)0893-1321(2009)22:4(383)

Guimarães ALS (1996) Modelagem de um aquecedor para banco de testes de estato-reatores a combustão supersônica (Master's Dissertation]. São José dos Campos: Instituto Nacional de Pesquisas Espaciais. In Portuguese.

Guimarães JS (2018) Investigação do escoamento a frio em uma bancada de testes de combustores supersônicos (Master's Dissertation) São José dos Campos: Instituto Tecnológico de Aeronáutica. In Portuguese.

Kidd FG, Danehy PM, Inman JA, Bathel BF, Cabell KF, Hass NE, Capriotti DP, Drozda TG, Johansen CT (2014) Characterization of the NASA Langley arc heated scramjet test facility using NO PLIF. Paper presented 30 th $A I A A$ Aerodynamic Measurement Technology and Ground Testing Conference. AIAA; Atlanta, USA. https://doi.org/10.2514/6.2014-2652

Kirk HF (1968) Ramjet Technology. Springfield: NTIS. Chapter 13, Facilities and testing, p. 1-37.

Leite VSFO (2006) Caracterização do escoamento de uma bancada de testes de combustores supersônicos alimentada por ar viciado (Thesis) São José dos Campos: Instituto Tecnológico e Aeronáutica. In Portuguese.

MacDermott WN, Horn DD, Fisher CJ (1992) Flow contamination and flow quality in arc heaters used for hypersonic testing. Paper presented AIAA 17th Aerospace Ground Testing Conference. AIAA; Nashville, Tennessee. https://doi.org/10.2514/6.1992-4028

Machado DA (2014) Velocimetria de Escoamentos em Câmara de Expansão (Master's Dissertation). São José dos Campos: Instituto Tecnológico de Aeronáutica. In portuguese.

Marcos TVC, Martos JFA, Toro PGP, Oliveira AC, Rego IS (2017) 3-D Prototyping Model Design for Experimental Investigation in Hypersonic Shock Tunnel. Paper presented 21st AIAA International Space Planes and Hypersonics Technologies Conference. AIAA; Xiamen, China. https://doi.org/10.2514/6.2017-2123

Resende AA, Vilarinho LO (2005) Técnica Schlieren aplicada à visualização de escoamentos em bocais de soldagem. Paper presented $15^{\circ}$ POSMEC - Simpósio do Programa de Pós-Graduação em Engenharia Mecânica. FEMEC/UFU; Uberlândia, Minas Gerais. [accessed Mar 17 2020]. https://ss/4799.websiteseguro.com/swge5/PROCEEDINGS/PDF/POSMEC2005-0022.pdf

Rogers RC, Capriotti DP, Guy RW (1998) Experimental supersonic combustion research at NASA Langley. Paper presented 20th AIAA Advanced Measurement and Ground Testing Technology Conference. AIAA; Albuquerque, New Mexico, USA. https://doi. org/10.2514/6.1998-2506

Santos AM (2008) A Pesquisa e desenvolvimento em hipersônica no IEAv. Revista Brasileira de Aplicações de Vácuo 27(1):5-10.

Sutton GP, Biblarzs O (2001) Rocket propulsion elements. New York: John Wiley \& Sons.

Tomioka S, Hiraiwa T, Kobayashi K, Izumikawa M, Kishida T, Yamasaki H (2007) Vitiation effects on scramjet engine performance in Mach 6 flight conditions. J Propul Power 23(4):789-796. https://doi.org/10.2514/1.28149 